\title{
Simulation-Based Medical Education Improves Procedural Confidence in Core Invasive Procedures for Military Internal Medicine Residents
}

Lauren A. Sattler ${ }^{1}$, Chad Schuety ${ }^{1}$, Mark Nau ${ }^{2}$, Daniel V. Foster ${ }^{3}$, John Hunninghake ${ }^{3}$, Tyson Sjulin ${ }^{3}$, Joshua Boster ${ }^{1}$

1. Internal Medicine, Brooke Army Medical Center, Fort Sam Houston, USA 2. Pulmonary and Critical Care Medicine, Walter Reed National Military Medical Center, Bethesda, USA 3. Pulmonary and Critical Care Medicine, Brooke Army Medical Center, Fort Sam Houston, USA

Corresponding author: Joshua Boster, josh.boster@gmail.com

\section{Abstract}

\section{Introduction}

The American Board of Internal Medicine (ABIM) requires that trainees receive procedural training for certification; however, Internal Medicine (IM) residents perform a variable number of procedures throughout residency training. This results in differences in confidence levels as well as procedural competence. For active-duty military trainees, this is especially problematic, as these procedural skills are often required during deployment soon after residency graduation. This deficit can be improved through standardized simulation-based training.

\section{Methods}

All internal medicine residents at our institution were invited to participate in a standardized simulationbased training program for core internal medicine procedures (lumbar puncture, arterial line, central line, thoracentesis, paracentesis, and arthrocentesis). Residents were asked to qualitatively rate their perceived procedural confidence using a Likert scale ranging from 1 (not at all confident) to 5 (extremely confident) in their ability to independently perform core internal medicine procedures prior to the simulation exercise. Experienced senior residents and internal medicine faculty instructed and supervised each resident as they performed the procedures. Following the simulation exercise, the residents repeated the survey and were asked to report whether or not they found the exercise useful.

\section{Results}

Received 10/26/2020

Review began 10/29/2020 Review ended 12/02/2020 Published 12/09/2020

\section{(๑) Copyright 2020}

Sattler et al. This is an open access article distributed under the terms of the Creative Commons Attribution License CC-BY 4.0., which permits unrestricted use, distribution, and reproduction in any medium, provided the original author and source are credited.
Of the 96 residents invited to participate, 49 completed the pre-simulation questionnaire and 36 completed the post-simulation questionnaire. The cumulative mean Likert scale confidence rating for all procedures showed a statistically significant improvement post-simulation as compared to pre-simulation, including lumbar puncture $(2.45 \pm 1.1$ vs. $3.42 \pm 0.87$, $\mathrm{p}<0.05)$, arterial line $(2.48 \pm 1.06$ vs. $3.39 \pm 1.04, \mathrm{p}<0.05)$, central line $(2.86 \pm 1.08$ vs. $3.5 \pm 1.02, \mathrm{p}<0.05)$, thoracentesis $(2.67 \pm 1.10$ vs. $3.64 \pm 0.83, \mathrm{p}<0.05)$, paracentesis $(3.1 \pm 1.08$ vs. $3.82 \pm 0.74, \mathrm{p}<0.05)$, and arthrocentesis $(2.56 \pm 1.07$ vs. $3.67 \pm 0.80, \mathrm{p}<0.05)$. All $(36 / 36)$ trainees reported that they perceived the simulation exercise as valuable.

\section{Conclusion}

Internal medicine residents across all post-graduate year (PGY) levels at our institution lacked confidence to independently perform core internal medicine procedures. Utilizing simulation-based medical education as an adjunct to clinical training is well accepted by internal medicine trainees, and resulted in significantly improved procedural confidence. This intervention was well received by trainees and could feasibly be replicated at other active-duty military internal medicine residency programs to assist with readiness. Research is currently in progress to correlate in-situ competency and evaluate clinical outcomes of this improved confidence.

Categories: Internal Medicine, Medical Education, Medical Simulation

Keywords: simulation education, military medicine, procedural competency

\section{Introduction}

The American Board of Internal Medicine (ABIM) requires that Internal Medicine (IM) residents receive procedural training; however, residents are not mandated to perform all procedures, and only general competence is required [1]. This has led to significant heterogeneity in the procedural skills training that IM residents receive with a consistent emphasis on experiential learning, particularly the "see one, do one, 
teach one" model [2-4]. However, reported clinical procedural experience has been demonstrated to be an unreliable proxy for procedural skill [5]. Additionally, due to this variability in clinical experience and in the training received during residency, levels of confidence and competence in performing common bedside procedures differ greatly among trainees [6].

This lack of standardized training experience directly impacts patient outcomes due to the invasive nature of these procedures and the associated risk for complications [7-9]. Additionally, for active-duty military IM residents, the lack of procedural confidence is of particular concern because IM specialists and subspecialists often deploy as intensivists with the expectation to maintain procedural competence for deployment readiness per the Air Force's Comprehensive Medical Readiness Program (CMRP) as well as the Army's Individual Critical Task List (ICTL).

In order to address these deficits, high-fidelity simulation-based mastery learning (SBML) has been identified as a way to standardize procedural experience and produce measurable quality outcomes $[10,11]$. SBML has been utilized to improve outcomes in multiple facets of medical training, including communication skills and ultrasound techniques $[12,13]$. Furthermore, SBML has been used to improve training in advanced cardiac life support (ACLS) due to perceived trainee discomfort and reported deficits $[14,15]$. Given the success with high-fidelity SBML in these areas of medical training, this teaching technique has been incorporated into procedural training to address these deficits. Significant improvements have been demonstrated in procedural competence and confidence among trainees by using SBML to learn multiple procedures, including central line placement, lumbar puncture, paracentesis, thoracentesis, and arthrocentesis in the civilian sector [16-20]. Given the requirement for procedural competence placed upon active-duty internists, and the emphasis on the use of simulation to augment clinical skills, we explored the utility of simulation in improving perceived procedural confidence in activeduty IM residents.

Due to the demonstrated benefits of high-fidelity simulation and deliberate practice in teaching procedural skill, efforts have been made to use SBML to instruct trainees in core internal medicine procedures [21,22]. However, there remains no standardized, simulation-based curriculum utilized across Internal Medicine residency training programs within the military healthcare system. We report the results of the adoption of a simulation-based medical education curriculum for core IM invasive bedside procedures and its implementation at a single IM residency program for active-duty military resident physicians.

\section{Materials And Methods}

All IM residents in post-graduate year (PGY) 1-3 at Brooke Army Medical Center in San Antonio, Texas, were invited to participate in the simulated training course. The course included multiple two-hour sessions that were conducted over two separate days with each session including three of six procedural skills: lumbar puncture, arterial line, central line, thoracentesis, paracentesis and arthrocentesis. Participants were divided into small groups comprised of two or three residents that rotated through each skill station. Experienced senior residents and IM faculty instructed and supervised each resident as they performed the procedures. Skills education and training were performed on a combination of high-fidelity SimMan3G mannequins (Laerdal), CentraLineMan system (Simulab), and Ultrasound ArteriaLine Trainer (Simulab).

Prior to the simulation sessions, the participants completed a questionnaire with non-identifiable demographic information, consent, and perceived procedural confidence level using a Likert scale with 1 correlating with (not at all confident), 2 (not so confident), 3 (somewhat confident), 4 (very confident), 5 (extremely confident) in their ability to independently perform core internal medicine procedures. Following the simulation session, the participants repeated the same questionnaire with an additional question about the overall perceived utility of the skills course. Data from the pre- and post-test survey were compared using Kruskal-Wallis tests with statistical significance set at $\mathrm{p}<0.05$.

\section{Results}

Of the 96 residents invited to participate, 49 completed the pre-simulation questionnaire and 36 completed the post-simulation questionnaire. The group was comprised of $26 \%, 33 \%$ and $41 \%$ of residents from the PGY1, PGY2 and PGY3 classes, respectively. All procedures showed a statistically significant improvement post-simulation as compared to pre-simulation, including lumbar puncture $(2.45 \pm 1.1 \mathrm{vs} .3 .42 \pm 0.87, \mathrm{p}<0.05)$, arterial line $(2.48 \pm 1.06$ vs. $3.39 \pm 1.04, \mathrm{p}<0.05)$, central line $(2.86 \pm 1.08$ vs. $3.5 \pm 1.02, \mathrm{p}<0.05)$, thoracentesis $(2.67 \pm 1.10$ vs. $3.64 \pm 0.83, \mathrm{p}<0.05)$, paracentesis $(3.1 \pm 1.08$ vs. $3.82 \pm 0.74, \mathrm{p}<0.05)$, and arthrocentesis $(2.56 \pm 1.07$ vs. $3.67 \pm 0.80, \mathrm{p}<0.05)$. All $(36 / 36)$ trainees reported that they perceived the simulation exercise as valuable on the post-simulation questionnaire (Table 1; Figure 1). 


\section{Cureus}

\begin{tabular}{|c|c|c|c|c|c|c|c|c|c|c|c|c|c|}
\hline \multicolumn{7}{|l|}{ Pre-Simulation } & \multicolumn{7}{|c|}{ Post-Simulation } \\
\hline & 1 & 2 & 3 & 4 & 5 & Average $\pm S D$ & 1 & 2 & 3 & 4 & 5 & Average $\pm S D$ & $\mathrm{p}$-value \\
\hline Central Line & 5 & 14 & 16 & 11 & 3 & $2.86 \pm 1.08$ & 1 & 5 & 15 & 9 & 6 & $3.5 \pm 1.02$ & 0.030 \\
\hline PGY1 & 5 & 5 & 1 & 2 & 0 & $1.62 \pm 1.08$ & 1 & 5 & 2 & 3 & 1 & $3.17 \pm 1.19$ & \\
\hline PGY2 & 0 & 4 & 10 & 1 & 1 & $2.94 \pm 0.19$ & 0 & 0 & 7 & 2 & 1 & $3.4 \pm 0.7$ & \\
\hline PGY3 & 0 & 5 & 5 & 8 & 2 & $3.35 \pm 0.99$ & 0 & 0 & 6 & 4 & 4 & $3.86 \pm 0.86$ & \\
\hline Arterial Line & 9 & 17 & 15 & 6 & 2 & $2.48 \pm 1.06$ & 1 & 5 & 16 & 7 & 7 & $3.39 \pm 1.04$ & $<0.001$ \\
\hline PGY1 & 5 & 7 & 1 & 0 & 0 & $1.69 \pm 0.63$ & 1 & 3 & 4 & 2 & 2 & $2.64 \pm 1.24$ & \\
\hline PGY2 & 2 & 7 & 5 & 1 & 1 & $2.5 \pm 1.03$ & 0 & 0 & 7 & 2 & 1 & $3.4 \pm 0.69$ & \\
\hline PGY3 & 2 & 3 & 9 & 5 & 1 & $3 \pm 1.03$ & 0 & 2 & 5 & 3 & 4 & $3.64 \pm 1.08$ & \\
\hline Lumbar Puncture & 13 & 9 & 21 & 4 & 2 & $2.45 \pm 1.1$ & 0 & 4 & 18 & 9 & 5 & $3.42 \pm 0.87$ & $<0.001$ \\
\hline PGY1 & 6 & 1 & 6 & 0 & 0 & $2 \pm 1$ & 0 & 3 & 3 & 5 & 1 & $3.33 \pm 0.98$ & \\
\hline PGY2 & 4 & 3 & 8 & 0 & 1 & $2.44 \pm 1.09$ & 0 & 1 & 6 & 2 & 1 & $3.3 \pm 0.82$ & \\
\hline PGY3 & 3 & 5 & 7 & 4 & 1 & $2.75 \pm 1.12$ & 0 & 0 & 9 & 2 & 3 & $3.57 \pm 0.85$ & \\
\hline Thoracentesis & 7 & 17 & 17 & 8 & 3 & $2.67 \pm 1.1$ & 0 & 1 & 20 & 18 & 6 & $3.64 \pm 0.83$ & 0.002 \\
\hline PGY1 & 4 & 10 & 5 & 0 & 0 & $2.05 \pm 1.17$ & 0 & 1 & 9 & 4 & 1 & $3.33 \pm 0.91$ & \\
\hline PGY2 & 2 & 1 & 9 & 2 & 0 & $2.79 \pm 0.91$ & 0 & 0 & 5 & 9 & 1 & $3.73 \pm 0.74$ & \\
\hline PGY3 & 1 & 6 & 3 & 6 & 3 & $3.21 \pm 0.9$ & 0 & 0 & 6 & 5 & 4 & $3.87 \pm 0.85$ & \\
\hline Paracentesis & 4 & 12 & 15 & 17 & 4 & $3.1 \pm 1.08$ & 0 & 1 & 17 & 16 & 11 & $3.82 \pm 0.74$ & $<0.001$ \\
\hline PGY1 & 4 & 6 & 5 & 3 & 1 & $2.53 \pm 0.71$ & 0 & 1 & 7 & 4 & 3 & $3.6 \pm 0.72$ & \\
\hline PGY2 & 0 & 3 & 5 & 5 & 1 & $3.29 \pm 0.89$ & 0 & 0 & 5 & 7 & 3 & $3.87 \pm 0.59$ & \\
\hline PGY3 & 0 & 3 & 5 & 9 & 2 & $3.53 \pm 1.23$ & 0 & 0 & 5 & 5 & 5 & $4 \pm 0.83$ & \\
\hline Arthrocentesis & 9 & 15 & 17 & 7 & 2 & $2.56 \pm 1.07$ & 0 & 2 & 18 & 18 & 7 & $3.67 \pm 0.8$ & $<0.001$ \\
\hline PGY1 & 7 & 7 & 4 & 0 & 1 & $2 \pm 1.05$ & 0 & 2 & 6 & 4 & 3 & $3.53 \pm 0.99$ & \\
\hline PGY2 & 2 & 3 & 7 & 2 & 0 & $2.64 \pm 0.93$ & 0 & 0 & 6 & 9 & 0 & $3.6 \pm 0.51$ & \\
\hline PGY3 & 0 & 5 & 6 & 5 & 1 & $3.18 \pm 0.93$ & 0 & 0 & 6 & 5 & 4 & $3.87 \pm 0.83$ & \\
\hline
\end{tabular}

TABLE 1: Comparison of self-reported confidence by Likert scale among residents, by PGY year for each individual core invasive procedure

PGY, post-graduate year; SD, standard deviation 


\section{Cureus}

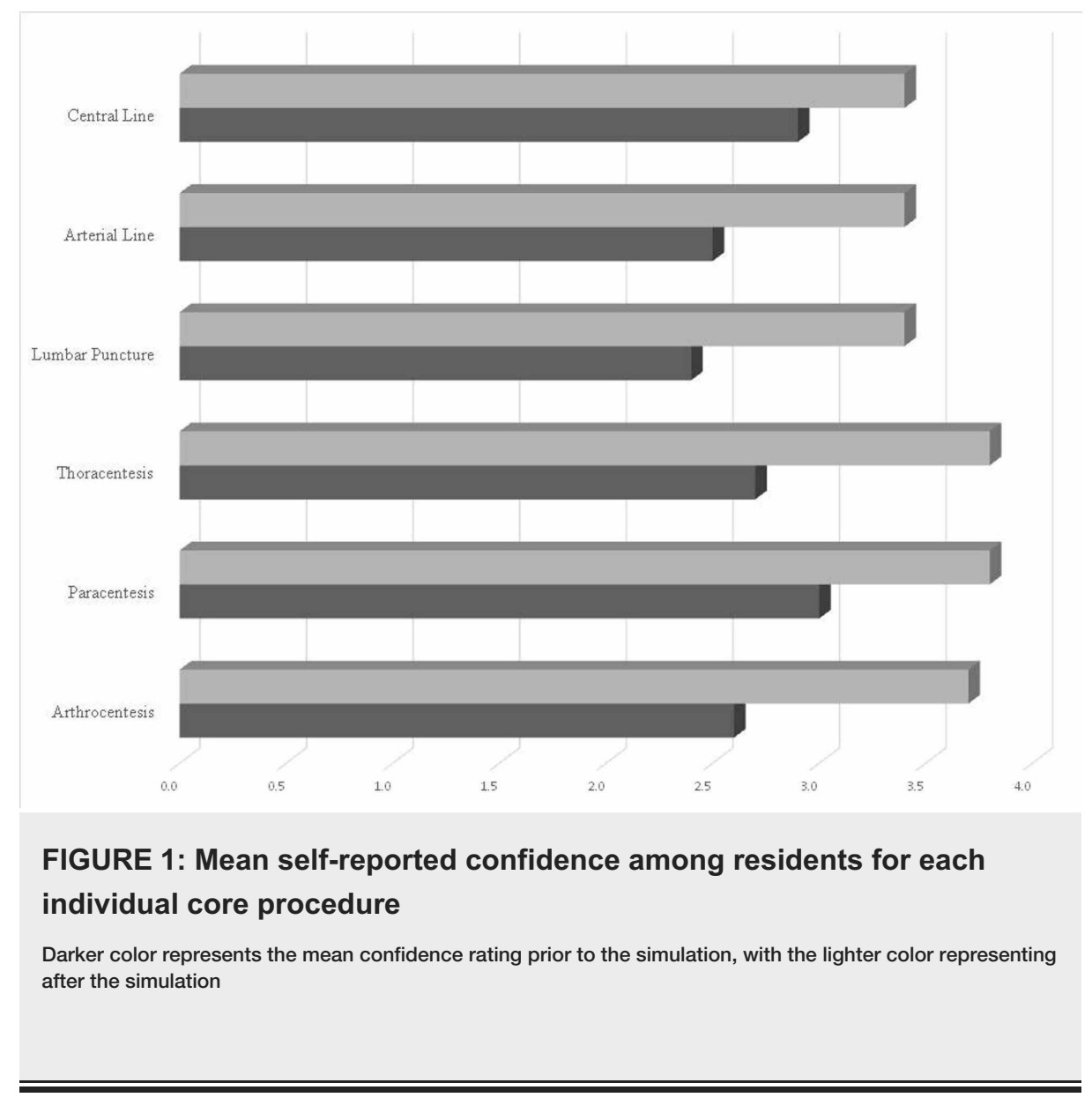

\section{Discussion}

Despite evidence that high-fidelity simulation is an effective, well-received tool for procedural training as well as skills maintenance, a standardized simulation curriculum does not currently exist for training active duty IM residents in core procedures $[23,24]$. Our study adds to the growing body of evidence that supports the use of high-fidelity simulation and deliberate practice in a structured learning environment to improve trainee procedural confidence. Use of this model has previously been used most commonly to instruct trainees in individual procedures; however, our study demonstrates the feasibility of developing and implementing a curriculum for all core IM procedures. The course has subsequently become a sustainable adjunct to the curriculum at our institution and is held on an annual basis.

An important finding of our study was that significant improvement in procedural confidence was demonstrated consistently for each PGY level, including residents that had completed most of their training. This supports findings of previous studies demonstrating that deliberate practice in a controlled environment is a useful adjunct to procedural learning regardless of experience in the clinical setting [14]. Utilizing simulation-based procedural training as part of a standardized curriculum is of particular importance for military IM residents, as these procedures are often necessary during deployment soon after completion of residency. Consistent implementation of a curriculum such as ours could be useful in mitigating self-identified lack of procedural confidence among trainees [4-6].

Though our simulation curriculum demonstrates a practical model that could be replicated at other training programs, one potential limitation is the resources required. In order to implement this study, we used highfidelity simulation mannequins from the simulation center at our institution, which may not be available at other institutions. The curriculum also involved supervision by IM faculty, which required approximately two hours of time volunteered for each session. The small-group training model with a high instructor-tolearner ratio was well-received by our residents; however, coordination of these resources may be an obstacle to course implementation at other institutions. This study was additionally limited by the relatively small sample size at a single institution and did not include a validation process for each procedural skill; however, this is a current goal for further study.

These limitations do not lessen the effect of the standardized curriculum on perceived confidence with bedside procedural skills; however, self-assessment does not always directly result in improved clinical performance $[25,26]$. Further research is needed to determine whether performance of all simulated core IM procedures translates to the clinical environment, including safety outcomes such as procedural 
complications and associated infections. Prior studies have demonstrated reduced rates of procedure-related complications through deliberate practice in a simulated environment [27-29]. However, these outcomes have primarily been studied in central venous catheter insertion and further outcomes research is needed for many of the other core IM procedures. Lastly, additional studies are needed to determine if deliberate practice during residency improves procedural confidence and competence among active-duty staff IM physicians in the pre-deployment setting.

\section{Conclusions}

Internal medicine residents across all post-graduate year levels at our institution lacked confidence to independently perform core internal medicine procedures. Utilizing simulation-based medical education as an adjunct to clinical training is well accepted by internal medicine trainees, and resulted in significantly improved procedural confidence across all post-graduate levels. This intervention was well received by trainees and could feasibly be replicated at other active-duty military internal medicine residency programs to assist with readiness. Research is currently in progress to correlate in-situ competency and evaluate clinical outcomes of this improved confidence.

\section{Additional Information \\ Disclosures}

Human subjects: All authors have confirmed that this study did not involve human participants or tissue. Animal subjects: All authors have confirmed that this study did not involve animal subjects or tissue. Conflicts of interest: In compliance with the ICMJE uniform disclosure form, all authors declare the following: Payment/services info: All authors have declared that no financial support was received from any organization for the submitted work. Financial relationships: All authors have declared that they have no financial relationships at present or within the previous three years with any organizations that might have an interest in the submitted work. Other relationships: All authors have declared that there are no other relationships or activities that could appear to have influenced the submitted work.

\section{Acknowledgements}

The views expressed are solely those of the authors and do not reflect the official policy or position of the U.S. Army, U.S. Air Force, the Department of Defense or the U.S. Government.

\section{References}

1. American Board of Internal Medicine. Internal medicine policies . (2020). Accessed: September 22, 2020: https://www.abim.org/ /media/ABIM\%20Public/Files/pdf/publications/certification-guides/policies-andprocedures.pdf.

2. McGaghie WC, Issenberg SB, Cohen ER, Barsuk JH, Wayne DB: Does simulation-based medical education with deliberate practice yield better results than traditional clinical education? A meta-analytic comparative review of the evidence. Acad Med. 2011, 86:706-711. 10.1097/ACM.0b013e318217e119

3. Rodriguez-Paz JM, Kennedy M, Salas E, Wu AW, Sexton JB, Hunt EA, Pronovost PJ: Beyond "see one, do one, teach one”: toward a different training paradigm. BMJ Qual Saf. 2009, 18:63-68. 10.1136/qshc. 2007.023903

4. Brydges R, Stroud L, Wong BM, Holmboe ES, Imrie K, Hatala R: Core competencies or a competent core? A scoping review and realist synthesis of invasive bedside procedural skills training in internal medicine. Acad Med. 2017, 92:1632-1643. 10.1097/ACM.0000000000001726

5. Barsuk JH, Cohen ER, Feinglass J, McGaghie WC, Wayne DB: Residents' procedural experience does not ensure competence: a research synthesis. J Grad Med Educ. 2017, 9:201-208. 10.4300/JGME-D-16-00426.1

6. Huang GC, Smith CC, Gordon CE, Feller-Kopman DJ, Davis RB, Phillips RS, Weingart SN: Beyond the comfort zone: residents assess their comfort performing inpatient medical procedures. Am J Med. 2006, 119:71.e17-71.e24. 10.1016/j.amjmed.2005.08.007

7. Alsaad AA, Bhide VY, Moss JL Jr, Silvers SM, Johnson MM, Maniaci MJ: Central line proficiency test outcomes after simulation training versus traditional training to competence. Ann Am Thorac Soc. 2017, 14:550-554. 10.1513/AnnalsATS.201612-9870C

8. Flannery MT, Villarreal KF: Training using simulation in internal medicine residencies: an educational perspective. Am J Med Sci. 2015, 349:276-278. 10.1097/MAJ.0000000000000406

9. Boulet JR, Murray D, Kras J, Woodhouse J, McAllister J, Ziv A: Reliability and validity of a simulation-based acute care skills assessment for medical students and residents. Anesthesiology. 2003, 99:1270-1280. 10.1097/00000542-200312000-00007

10. Ogden PE, Cobbs LS, Howell MR, Sibbitt SJ, DiPette DJ: Clinical simulation: importance to the internal medicine educational mission. Am J Med. 2007, 120:820-824. 10.1016/j.amjmed.2007.06.017

11. Markin A, Cabrera-Fernandez DF, Bajoka RM, et al.: Impact of a simulation-based communication workshop on resident preparedness for end-of-life communication in the intensive care unit. Crit Care Res Pract. 2015, 2015:534879. 10.1155/2015/534879

12. Sukalich S, Elliott JO, Ruffner G: Teaching medical error disclosure to residents using patient-centered simulation training. Acad Med. 2014, 89:136-143. 10.1097/ACM.0000000000000046

13. Mellor TE, Junga Z, Ordway S, et al.: Not Just Hocus POCUS: Implementation of a Point of Care Ultrasound Curriculum for Internal Medicine Trainees at a Large Residency Program. Mil Med. 2019, 184:901-906. 10.1093/milmed/usz124 
14. Wayne DB, Didwania A, Feinglass J, Fudala MJ, Barsuk JH, McGaghie WC: Simulation-based education improves quality of care during cardiac arrest team responses at an academic teaching hospital: a casecontrol study. Chest. 2008, 133:56-61. 10.1378/chest.07-0131

15. Hayes CW, Rhee A, Detsky ME, Leblanc VR, Wax RS: Residents feel unprepared and unsupervised as leaders of cardiac arrest teams in teaching hospitals: a survey of internal medicine residents. Crit Care Med. 2007, 35:1668-1672. 10.1097/01.CCM.0000268059.42429.39

16. Barsuk JH, McGaghie WC, Cohen ER, O'Leary KJ, Wayne DB: Simulation-based mastery learning reduces complications during central venous catheter insertion in a medical intensive care unit. Crit Care Med. 2009, 37:2697-2701. 10.1097/CCM.0B013E3181A57BC1

17. Barsuk JH, Cohen ER, Caprio T, McGaghie WC, Simuni T, Wayne DB: Simulation-based education with mastery learning improves residents' lumbar puncture skills. Neurology. 2012, 79:132-137. 10.1212/WNL.0b013e31825dd39d

18. Barsuk JH, Cohen ER, Vozenilek JA, O'Connor LM, McGaghie WC, Wayne DB: Simulation-based education with mastery learning improves paracentesis skills. J Grad Med Educ. 2012, 4:23-27. 10.4300/JGME-D-1100161.1

19. Wayne DB, Barsuk JH, O'Leary KJ, Fudala MJ, McGaghie WC: Mastery learning of thoracentesis skills by internal medicine residents using simulation technology and deliberate practice. J Hosp Med. 2008, 3:48-54. 10.1002/jhm.268

20. Stroud L, Cavalcanti RB: Hybrid simulation for knee arthrocentesis: improving fidelity in procedures training. J Gen Intern Med. 2013, 28:723-727. 10.1007/s11606-012-2314-Z

21. Mathai SK, Miloslavsky EM, Contreras-Valdes FM, Milosh-Zinkus T, Hayden EM, Gordon JA, Currier PF: How we implemented a resident-led medical simulation curriculum in a large internal medicine residency program. Med Teach. 2014, 36:279-283. 10.3109/0142159X.2013.875619

22. Dversdal RK, Gold JA, Richards MH, et al.: A 5-day intensive curriculum for interns utilizing simulation and active-learning techniques: addressing domains important across internal medicine practice. BMC Res Notes. 2018, 11:916. 10.1186/s13104-018-4011-4

23. Shanks D, Wong RY, Roberts JM, Nair P, Ma IW: Use of simulator-based medical procedural curriculum: the learner's perspectives. BMC Med Educ. 2010, 10:77. 10.1186/1472-6920-10-77

24. McGaghie WC, Siddall VJ, Mazmanian PE, Myers J: Lessons for continuing medical education from simulation research in undergraduate and graduate medical education: effectiveness of continuing medical education: American College of Chest Physicians Evidence-Based Educational Guidelines. Chest. 2009, 135:62S-68S. 10.1378/chest.08-2521

25. Bond WF, Lammers RL, Spillane LL, et al.: The use of simulation in emergency medicine: a research agenda . Acad Emerg Med. 2007, 14:353-363. 10.1197/j.aem.2006.11.021

26. Wayne DB, Butter J, Siddall VJ, et al.: Graduating internal medicine residents' self-assessment and performance of advanced cardiac life support skills. Med Teach. 2006, 28:365-369. $10.1080 / 01421590600627821$

27. Jagneaux T, Caffery TS, Musso MW, et al.: Simulation-based education enhances patient safety behaviors during central venous catheter placement [ahead of print]. J Patient Saf. 2020, 10.1097/pts.0000000000000425

28. Smith CC, Huang GC, Newman LR, et al.: Simulation training and its effect on long-term resident performance in central venous catheterization. Simul Healthc. 2010, 5:146-151. 10.1097/SIH.0b013e3181dd9672

29. Laack TA, Dong Y, Goyal DG, Sadosty AT, Suri HS, Dunn WF: Short-term and long-term impact of the central line workshop on resident clinical performance during simulated central line placement. Simul Healthcare. 2014, 9:228-233. 10.1097/SIH.0000000000000015 